\title{
Characterization of Parallel and Antiparallel G-tetraplex Structures by Vibrational Spectroscopy.
}

M. Romero Guzmán ${ }^{(\mathrm{a})}$, J. Liquier ${ }^{(\mathrm{a})^{\star}}$, S.K. Brahmachari ${ }^{(\mathrm{b})}$ and E. Taillandier ${ }^{(\mathrm{c})}$

a Laboratoire BioMoCeTi, UMR CNRS 7033, Université Paris 13, 74, rue Marcel Cachin, F93017 Bobigny Cedex, France.

b G.N. Ramachandran Knowledge Centre for Genome Informatics, Institute of Genomics and Integrative Biology, Mall Road, Delhi 110 007, India.

c UFR de Médecine, Université Paris 13, 74 rue Marcel Cachin, F93017 Bobigny Cedex, France

* Author to whom correspondence should be addressed:

Phone : (33) $0148387691 \mathrm{FAX}$ : (33) 0148387777

e-mail : liquier@smbh.univ-paris13.fr 


\section{Abstract}

A series of G-rich oligonucleotides able to form tetraplexes has been studied by FTIR spectroscopy. Characteristic markers of the formation of guanine tetrads are given. Moreover we propose a new marker discriminating between parallel and antiparallel tetraplexes: the position of the $\mathrm{C} 6=\mathrm{O} 6$ guanine carbonyl stretching vibration. In intermolecular parallel tetrameric structures formed by four separate strands this absorption is observed at $1693 \mathrm{~cm}^{-1}$ while for antiparallel tetrameric structures, either intramolecular or formed by dimerization of hairpins, this vibrational mode is observed at $1682 \mathrm{~cm}^{-1}$. These shifts to higher wavenumbers, when compared to the position of a free guanine $\mathrm{C} 6=\mathrm{O} 6$ carbonyl stretching vibration observed at $1666 \mathrm{~cm}^{-1}\left(\Delta v=27 \mathrm{~cm}^{-1}\right.$ for parallel tetraplexes and $\Delta v=16 \mathrm{~cm}^{-1}$ for antiparallel tetraplexes) reflect different strand orientations in the structures. This marker has been used to evidence the possibility of an antiparallel - parallel tetraplex reorganization for Oxytricha nova $d\left(G_{4} T_{4} G_{4}\right)$ and $d\left(\left(G_{4} T_{4}\right)_{3} G_{4}\right)$ and human $\mathrm{d}\left(\mathrm{G}_{3} \mathrm{~T}_{2} \mathrm{AG}_{3}\right)$ telomeric sequences induced by $\mathrm{Na}^{+} / \mathrm{K}^{+}$or $\mathrm{Na}^{+} / \mathrm{Ca}^{2+}$ ion exchange. Formation of the guanine tetrads, characterization of the phosphate geometries and of the sugar conformations have also been obtained by FTIR for the different tetraplexes.

\section{Key words:}

guanine, tetraplex, parallel, antiparallel, FTIR 


\section{Introduction}

DNA sequences containing runs of guanine rich segments can form unusual DNA structures, tetraplexes, based on the association of guanine tetrads (scheme 1). Such sequences are found in particular at the extreme 3'end of telomeric DNA, which consists in single-stranded guanine rich DNA overhangs, for instance tandem repeats of $d\left(T_{2} A_{3}\right)$ in humans or $d\left(G_{4} T_{4}\right)_{n}$ in Oxytricha nova (for review $[1,2]$ ). Increased interest in the structure of telomeric DNA is due to the identification of a putative biological role and thus of possible biotechnical and therapeutic applications. G tetraplex DNA is a potential target for anticancer drug design (for review [3]). These structures seem to participate in telomere protection and in elongation and transcriptional regulation. Tetraplex DNA structures have been detected in chromosomal DNA extracted from human cells using a fluorescent carbazole derivative, suggesting the existence of tetraplex structures in human nuclei [4]. Interference with telomerase and telomere maintenance is emerging as an attractive target for anticancer therapies. It has been recently shown that ligand induced stabilization of G tetraplex formation by telomeric DNA 3' overhangs inhibits telomerase from catalyzing telomeric DNA synthesis in the human uterus carcinoma cell line UXF1138L [5]. The heterogeneous hnRNP A1 binds to $G$ rich repetitive sequences and $G$ tetraplex structures in DNA including the $d\left(T_{2} A G_{3}\right)$ telomere repeat, and DNA synthesis arrest at the GGG sites is retrieved by addition of this protein in a dose-dependent manner. Overexpression of hnRNP A1 in colorectal cancers could contribute to maintenance of telomere repeats in cancer cells with enhanced cell proliferation [6]. Cytoplasmic intermediate filament proteins interact strongly with $\mathrm{G}$ rich sequences, but differential binding affinities of the clF proteins to parallel four-stranded, bimolecular and unimolecular tetraplex configurations have 
been shown by band shift assays [7]. The TRF2 telomere binding protein recognizes telomeric single-stranded/double-stranded DNA junctions, but telomeric complexes containing TRF2 and pot1 assemble less efficiently when the G strand overhang forms an intramolecular $G$ tetraplex [8]. An intramolecular parallel stranded G tetraplex has been found to form in the human c-MYC promoter providing a basis for the design of drug candidates targeting the c-MYC G tetraplex to modulate gene expression $[9,10]$. A porphyrin analog has been shown to bind to a $G$ tetraplex in the c-MYC promoter and convert it from a parallel to a mixed parallel/antiparallel G tetraplex, suppressing the c-MYC transcriptional activation [11].

A variety of $G$ tetraplex structures exists in vitro. In all cases they are stabilized by the presence of guanine tetrads characterized by the cyclic hydrogen-bonding of four guanine bases in a planar arrangement (scheme 1). They can be classified following whether the tetraplex is formed from one, two or four separate strands and following the pattern of strand orientation (for review [12-15]). $G$ tetraplexes can be formed by the intermolecular association of four DNA molecules (tetrameric structure) [16-18], of two hairpins (dimeric structure) [19-21] or by the intramolecular folding of a single strand containing four blocks of guanines (monomeric structure) [22-24]. G tetraplexes are highly polymorphic with respect to three mutually related factors: the orientations of strands, the syn/anti glycosidic conformation of guanosine residues and the loop connectivities. In antiparallel $G$ tetraplexes, guanosines usually alternate between syn and anti conformations whereas in parallel G tetraplexes all guanosines adopt the anti conformation. The structure and stability of $\mathrm{G}$ tetraplexes depend on the nature and amount of cations present (for review [25]). Potassium has the ability not only to stabilize the $G$ tetraplex structure but also to induce its structural transition from an antiparallel to parallel structures [26, 27]. Structural studies have suggested that the human telomeric sequence $d\left(A_{3}\left(T_{2} A G_{3}\right)_{3}\right)$ folds 
into an antiparallel arrangement in presence of sodium [28] but a parallel structure in presence of potassium [29]. Divalent cations can also induce a transition from an antiparallel to a parallel $\mathrm{G}$ tetraplex structure. For instance $\mathrm{Ca}^{2+}$ induces a structural switch between the antiparallel and parallel forms of the Oxytricha nova telomeric sequence [30].

Vibrational spectroscopy has proved to be a very powerful technique to characterize DNA structures. Different makers of duplex and triplex DNA structures have been obtained by FTIR spectroscopy. These maker bands allow to detect formation of hydrogen bonds on the bases and thus to characterize different base paring schemes and to identify directly the sugar conformations ( $N$ or $S$ family type) [31]. In this work, we have studied by FTIR spectroscopy a series of $G$ rich sequences known from the literature to form parallel or antiparallel tetraplexes. This allows us to propose a new spectroscopic marker, the position of the $\mathrm{C} 6=\mathrm{O} 6$ guanine carbonyl stretching vibration, which permits to distinguish between these two families of tetraplexes. This absorption is detected at $1693 \mathrm{~cm}^{-1}$ for parallel tetraplexes and $1682 \mathrm{~cm}^{-1}$ in the case of antiparallel tetraplexes, while it is observed at $1666 \mathrm{~cm}^{-1}$ for a free guanine carbonyl. We have then investigated, using this new conformational marker, the possibility for Oxytricha nova $d\left(G_{4} T_{4} G_{4}\right)$ and $d\left(\left(G_{4} T_{4}\right)_{3} G_{4}\right)$ and human $d\left(G_{3} T_{2} A G_{3}\right)$ telomeric sequences to undergo a transition between these two geometries, from antiparallel to parallel, induced by potassium or divalent calcium ions.

\section{Materials and Methods}

Oligonucleotides. The Oxytricha nova $\mathrm{d}\left(\mathrm{G}_{4} \mathrm{~T}_{4} \mathrm{G}_{4}\right)$ and $\mathrm{d}\left(\left(\mathrm{G}_{4} \mathrm{~T}_{4}\right)_{3} \mathrm{G}_{4}\right)$ and the human $d\left(G_{3} T_{2} A G_{3}\right)$ telomeric sequences were prepared as previously described [26]. 
Oligonucleotides $d\left(T_{9} G_{5}\right), d\left(G_{4} T G_{4}\right)$ and $d\left(G_{4} T_{3} G_{4}\right)$ were purchased from Eurogentec (OliGold grade) and purified using an Ultrafree-MC filter (Millipore). Samples were prepared at neutral $\mathrm{pH}$ and no buffer was used for FTIR experiments.

FTIR spectroscopy. Samples were studied in $\mathrm{H}_{2} \mathrm{O}$ and in $\mathrm{D}_{2} \mathrm{O}$ solutions at a strand concentration of about $15 \mathrm{mM}$. The ions used for the experiments were $\mathrm{Na}^{+}, \mathrm{K}^{+}$and $\mathrm{Ca}^{2+}$ (chloride salts). Samples in $\mathrm{NaCl}$ (or $\mathrm{KCl}$ ) solutions contained one $\mathrm{Na}^{+}$(or $\mathrm{K}^{+}$) ion per nucleotide while samples prepared with $\mathrm{Ca}^{2+}$ contained one $\mathrm{Na}^{+}$per nucleotide plus $2 \mathrm{Ca}^{2+}$ per tetraplex. They were deposited between two ZnSe windows without spacer. Deuteration experiments were performed by drying the samples under nitrogen and redissolving in equivalent volumes of $D_{2} O(>99.8 \%$ pirity, Euriso-Top CEA). FTIR spectra were recorded with a Perkin-Elmer 2000 spectrophotometer under continuous dry air purge at a $1 \mathrm{~cm}^{-1}$ resolution. Ten scans were usually accumulated. Data treatment was performed using the Perkin-Elmer Spectrum program and consisted only in multiple-point base line correction.

\section{Results}

In a first part we shall present results concerning parallel tetraplexes. We shall then consider the characterization of antiparallel tetraplexes, and in a final section we shall discuss the structural transition between antiparallel and parallel structures induced by $\mathrm{K}^{+}$or $\mathrm{Ca}^{2+}$ ions in the case of telomeric sequences $\mathrm{d}\left(\mathrm{G}_{4} \mathrm{~T}_{4} \mathrm{G}_{4}\right)$ $\mathrm{d}\left(\left(\mathrm{G}_{4} \mathrm{~T}_{4}\right)_{3} \mathrm{G}_{4}\right)$ (Oxytricha nova) and $\mathrm{d}\left(\mathrm{G}_{3} \mathrm{~T}_{2} \mathrm{AG}_{3}\right)$ (human).

\subsection{FTIR characterization of tetraplexes : interpretation of vibrational markers in} parallel stranded structures. 


\subsubsection{Base carbonyl in-plane stretching vibrations.}

Figure 1 presents the FTIR spectra recorded in $\mathrm{D}_{2} \mathrm{O}$ solutions, in the region containing the in-plane double bond stretching vibrations of the bases, of oligonucleotides known from the literature to form parallel four-stranded intermolecular tetraplexes : $d_{12}$ (figure $1 \mathrm{a}$ ), $d\left(\mathrm{G}_{4} \mathrm{TG}_{4}\right)$, (figure $1 \mathrm{~b}$ ) [26] and $d\left(\mathrm{~T}_{9} \mathrm{G}_{5}\right.$ ) (figure 1c) [32]. Assignments of base vibrations are proposed by comparison with the spectra of $\mathrm{dT}_{12}$ (figure $2 \mathrm{a}$ ) and of $5^{\prime}-\mathrm{dGMP}$ recorded at $5^{\circ} \mathrm{C}$ and $95^{\circ} \mathrm{C}$ (figures $2 \mathrm{~b}, \mathrm{c}$ ). In this spectral domain, the most intense absorption involving guanosine vibrations is assigned to the $\mathrm{C} 6=\mathrm{O} 6$ stretching vibration. In the case of guanosines not involved in hydrogen bonding it is observed at a relatively low wavenumber: $1666 \mathrm{~cm}^{-1}$ for $5^{\prime}$-dGMP (spectrum recorded at $95^{\circ} \mathrm{C}$ figure $2 \mathrm{c}$ ), $1665 \mathrm{~cm}^{-1}$ or for $5^{\prime}-\mathrm{GMP}$ [33]. When the nucleotide is self-associated, forming a tetramer via Hoogsteen type G-G interactions (scheme 1), the carbonyl is involved in an hydrogen bond and this band is shifted to higher wavenumbers, at $1678 \mathrm{~cm}^{-1}$ for $5^{-}$-dGMP (figure $2 \mathrm{~b}$ ) or $1672 \mathrm{~cm}^{-1}$ for 5'-GMP [33].

In the spectrum of $\mathrm{dG}_{12}$ the $\mathrm{C} 6=\mathrm{O} 6$ carbonyl stretching vibration is located at 1692 $\mathrm{cm}^{-1}$ (figure 1a). This important shift to higher wavenumbers when compared to 5'-dGMP (either free, $\Delta v=26 \mathrm{~cm}^{-1}$, or involved in tetrads, $\Delta v=14 \mathrm{~cm}^{-1}$ ) reflects in $\mathrm{dG}_{12}$, first the existence of hydrogen bonds on the $\mathrm{C} 6=06$ carbonyls and second the important stacking interactions between the tetrad planes that occur in the parallel stranded tetraplex structure formed by $\mathrm{dG}_{12}$.

The studied oligonucleotides $d G_{12}, d\left(G_{4} T G_{4}\right)$ and $d\left(T_{9} G_{5}\right)$ contain increasing amounts of thymines: the thymine/guanine base ratio varies between 0 and 1.8 going from $d G_{12}$ to $d\left(T_{9} G_{5}\right)$. Three thymine absorptions are expected in the 1750 $1500 \mathrm{~cm}^{-1}$ region: a ring vibration and two carbonyl stretching vibrations [34]. They 
can be seen on the spectrum of $\mathrm{dT}_{12}$ (figure $2 \mathrm{a}$ ), located at $1632 \mathrm{~cm}^{-1}$ (ring vibration), $1663 \mathrm{~cm}^{-1}$ (C4=O4 carbonyl stretching) and $1695 \mathrm{~cm}^{-1}$ (C2=02 carbonyl stretching). The solution spectrum of $d\left(G_{4} T G_{4}\right)$ (figure $1 b$ ) is very similar to that of $d G_{12}$, with only a very weak contribution from thymidines. In the case of $d\left(T_{9} G_{5}\right)$ (figure $1 \mathrm{c}$ ), the thymine ring vibration is found at $1632 \mathrm{~cm}^{-1}$ and the $\mathrm{C} 4=04$ stretching vibration absorption at $1668 \mathrm{~cm}^{-1}$. The thymine $\mathrm{C} 2=\mathrm{O} 2$ stretching vibration band is overlapped by the guanine $\mathrm{C} 6=06$ band at $1692 \mathrm{~cm}^{-1}$.

The wavenumbers of the guanine $\mathrm{C} 6=\mathrm{O} 6$ carbonyl stretching vibration for the studied sequences are given in Table 1.

\subsubsection{Evidence of the formation of an hydrogen bond on the guanine N7 atom in the} tetraplexes.

When guanines are involved in tetrads, Hoogsteen type hydrogen bonds between $\mathrm{C} 6=\mathrm{O} 6$ and $\mathrm{N} 1-\mathrm{H}$ groups of two guanines on one hand, $\mathrm{N} 7$ and $\mathrm{N} 2-\mathrm{H}$ groups on the other are formed (scheme 1). The existence of this second hydrogen bond is evidenced by the emergence of a new absorption located at $1537 \mathrm{~cm}^{-1}$ absent from the spectrum of isolated 5'-dGMP (figure 2c). This absorption is observed for structures with G-G Hoogsteen type base pairs, such as G tetrads (self associated 5'-dGMP (figure 2b)), GpG in presence of $\mathrm{K}^{+}$ions [35,36], polyG [37], or triple helices containing $G * G . C$ base triplets [38]. On the contrary, it is not observed in structures with G-C Watson-Crick base pairing in which the N7 atom of guanines remains free, for instance duplexes such as $d\left(C_{n} G C G_{n}\right)$ with $n=2,35, d G_{n} \cdot d C_{n}$ or $d(G-C)_{n} \cdot d(C-G)_{n}$ [39]. In the case of $d G_{12}, d\left(G_{4} T G_{4}\right)$ and $d\left(T_{9} G_{5}\right)$ we observe this band (figure $1 \mathrm{a}, \mathrm{b}, \mathrm{c}$ ), which shows the establishment of an hydrogen bond between $\mathrm{N} 7$ and $\mathrm{N} 2-\mathrm{H}$ atoms of two guanines, and confirms the formation of the guanine tetrads. 
Another absorption is also sensitive to the interactions at the level of the guanine N7 atom. It is assigned to a vibration mode involving the $\mathrm{N} 7 \mathrm{C} 8 \mathrm{H}$ bending motion and can be easily observed in spectra recorded in $\mathrm{H}_{2} \mathrm{O}$ solutions. When the $\mathrm{N} 7$ atom is not involved in hydrogen bonding, for instance in Watson-Crick base paired double helices, it is located at $1496 \mathrm{~cm}^{-1}$, in A family form as well as in B family form duplex spectra (figure $3 a, b$ ). This band is shifted to lower wavenumbers when an hydrogen bond is formed on the $N 7$ site. In the spectra of $d G_{12}$ and $d\left(G_{4} T G_{4}\right)$ (figure $3 c, d$ ), we observe this band around $1485 \mathrm{~cm}^{-1}$ which again confirms the formation of the guanine tetrads and of the parallel tetraplexes.

\subsubsection{Sugar conformations.}

Vibrational spectroscopy can directly characterize the sugar pucker in nucleic acids using bands characteristic of $\mathrm{S}$ type (C2'endo) or $\mathrm{N}$ type (C3'endo) sugar conformations. Thus $S$ type sugars will be detected thanks to a band located around $838 \mathrm{~cm}^{-1}$ while $\mathrm{N}$ type sugars will generate bands around $865 \mathrm{~cm}^{-1}$ and $805 \mathrm{~cm}^{-1}$ [39]. In the spectra of $d G_{12}$ and $d\left(G_{4} T G_{4}\right)$ (figure $\left.4 a, b\right)$ we can observe the presence of a band around $834 \mathrm{~cm}^{-1}$ and the absence of any significant contribution around 865 and $805 \mathrm{~cm}^{-1}$. This clearly indicates that the sugars in these tetraplexes adopt

preferentially an S type (C2'endo) geometry. For comparison, an example of a tetraplex with $\mathrm{N}$ type sugars is presented figure 4c. It is formed by the intermolecular association of four $\mathrm{rG}_{7}$ strands. As expected for structures containing riboses this spectrum contains the characteristic absorptions of $\mathrm{N}$ type (C3'endo) sugars at 868 and $801 \mathrm{~cm}^{-1}$.

\subsubsection{Vibrations of the $\mathrm{PO}_{2}^{-}$phosphate groups and of the phosphodiester chain.}


In double stranded nucleic acid structures vibrations of the $\mathrm{PO}_{2}^{-}$phosphate groups are detected by the presence of two strong absorptions. The first band corresponds to the antisymmetric stretching vibration $\mathrm{v}_{\mathrm{as}} \mathrm{PO}_{2}^{-}$and is located in the $1245-1210 \mathrm{~cm}^{-1}$ region. This position of this band is sensitive to the hydration of the nucleic acid and therefore will vary depending on the geometry. For instance for a $d\left(C_{3} G C G_{3}\right)_{2}$ duplex formed by Watson-Crick G-C base pairs, in low water activity conditions (A form) it is found at $1235 \mathrm{~cm}^{-1}$ (figure $3 a$ ) while in aqueous solution (B family form) it is observed at $1220 \mathrm{~cm}^{-1}$ (figure $3 \mathrm{~b}$ ). The second band corresponding to the symmetric stretching vibration of the phosphate groups, $v_{\mathrm{S}} \mathrm{PO}_{2}^{-}$, is located at $1087 \mathrm{~cm}^{-1}$. In contrast to the antisymmetric stretching vibration band, the position of the symmetric stretching vibration band is almost not sensitive to changes in the nucleic acid double helical geometry.

In the spectra of the parallel tetraplexes studied here, the antisymmetric stretching vibration band is observed around $1225 \mathrm{~cm}^{-1}$ reflecting a "B-like" geometry for the $\mathrm{PO}_{2}^{-}$groups (figure 3c, d). However we must notice an unusual profile of the symmetric stretching vibration band which clearly contains two contributions respectively located at 1091 and $1082 \mathrm{~cm}^{-1}$ (figure 3c, d, right panel with an expanded scale). Moreover we observe in the spectra recorded in $\mathrm{H}_{2} \mathrm{O}$ solutions of all parallel quadruplexes studied, the presence of a band at $1180 \mathrm{~cm}^{-1}$. This absorption involves $\mathrm{C}-\mathrm{O}$ stretching vibration of the phosphodiester chain. The presence of the $1180 \mathrm{~cm}^{-1}$ absorption is indicative of a change in the phosphodiester conformation, although as shown above, the sugars remain in S type geometry. The X-ray diffraction study of the crystal structure of the parallel $d\left(T G_{4} T\right)$ tetraplex has shown the existence of a strain in the phosphate backbone torsion angles necessary to optimize guanine stacking [18]. This does not require any structural change in the sugar, but induces two discrete conformations in the phosphate backbone. The 
existence of two contributions at 1091 and $1082 \mathrm{~cm}^{-1}$ in the FTIR spectra of parallel tetraplexes, whatever the sequence, and for structures formed by DNAs as well as RNAs, may reflect these two phosphate backbone geometries.

\subsection{FTIR characterization of tetraplexes : interpretation of vibrational markers in} antiparallel stranded structures.

\subsubsection{Base in-plane double bond stretching vibrations.}

Figure 5 (left panel) presents the FTIR spectra recorded in presence of $\mathrm{Na}^{+}$ions of four oligonucleotides $\mathrm{d}\left(\mathrm{G}_{4} \mathrm{~T}_{3} \mathrm{G}_{4}\right), \mathrm{d}\left(\mathrm{G}_{4} \mathrm{~T}_{4} \mathrm{G}_{4}\right)$ and $\mathrm{d}\left(\left(\mathrm{G}_{4} \mathrm{~T}_{4}\right)_{3} \mathrm{G}_{4}\right)$ (the two latter are repeat motives of the Oxytricha nova telomere) and $d\left(G_{3} T_{2} A G_{3}\right)$ (repeat motif of the human telomere). In these conditions $d\left(G_{4} T_{3} G_{4}\right), d\left(G_{4} T_{4} G_{4}\right)$ and $d\left(G_{3} T_{2} A G_{3}\right)$ fold back on themselves as hairpins and are known to adopt in $\mathrm{NaCl}$ solution intermolecular antiparallel tetrameric structures formed by dimerization [26, 20, 40]. Guanine tetrads are then connected by two $T_{3}, T_{4}$ or TTA loops. The oligonucleotide $d\left(\left(G_{4} T_{4}\right)_{3} G_{4}\right)$ folds back three times on itself and forms an intramolecular antiparallel tetraplex with four guanine tetrads connected via three $T_{4}$ loops $[22,41]$.

The FTIR absorptions can be assigned as follows: the guanine band located at 1537 $\mathrm{cm}^{-1}$ discussed above, is characteristic of the involvement of the $\mathrm{N} 7$ atoms in hydrogen bonding. Guanine absorptions are found at $1582 \mathrm{~cm}^{-1}$ (ring $\mathrm{C}=\mathrm{C}$ stretching) and $1566 \mathrm{~cm}^{-1}$ (ring $\mathrm{C}-\mathrm{N}$ and $\mathrm{C}=\mathrm{N}$ stretching). The thymine absorptions are found around $1628 \mathrm{~cm}^{-1}$ (ring vibration) and $1663 \mathrm{~cm}^{-1}$ (C4=04 carbonyl stretching). In the case of the human telomere an adenine absorption assigned to a $\mathrm{ND}_{2}$ vibration coupled to a ring vibration is detected at $1621 \mathrm{~cm}^{-1}$ (figure $5 \mathrm{~d}$ ). 
Finally the strongest band, assigned to the $\mathrm{C} 6=\mathrm{O} 6$ carbonyl stretching vibration is observed in the spectra of these antiparallel tetraplexes at $1682 \mathrm{~cm}^{-1}$, a completely different position than for parallel tetraplexes. This wavenumber is intermediate between the values corresponding to a free carbonyl $\left(1666 \mathrm{~cm}^{-1}\right.$, figure $\left.2 \mathrm{c}\right)$ and to a carbonyl in a parallel tetraplex $\left(1693 \mathrm{~cm}^{-1}\right.$, figure 1$)$. It is known that stacking interactions change the IR spectra of carbonyl vibrations in bases: a shift of stretching vibrations of the $\mathrm{C}=\mathrm{O}$ groups occurs towards high wavenumbers in polynucleotides upon the transition from non ordered to highly ordered structures ([42] and ref within). In the present case, the degree of co-planarity between dG residues in each $G$ tetrad is greater in the parallel structures than in the antiparallel ones. The perturbation of each $\mathrm{G}$ tetrad directly affects the stacking energy of the neighboring $\mathrm{G}$ tetrad [43]. This is reflected on the FTIR spectra by the shift of the guanine $\mathrm{C} 6=\mathrm{O} 6$ carbonyl band. The position of this absorption can be used as marker to characterize the type of tetraplex formed (parallel or antiparallel). The wavenumbers of the guanine $\mathrm{C} 6=\mathrm{O} 6$ carbonyl stretching vibration for the studied antiparallel tetraplexes are also given in Table 1.

\subsubsection{Sugar conformations and vibrations of the phosphodiester backbone and of} the $\mathrm{PO}_{2}^{-}$phosphate groups.

Concerning the sugar geometries, in the spectra of $d\left(G_{4} T_{3} G_{4}\right), d\left(G_{4} T_{4} G_{4}\right)$ and $d\left(G_{3} T_{2} A G_{3}\right)$ we can observe the presence of a band around $836 \mathrm{~cm}^{-1}$ (figure $\left.4 d, e, f\right)$. This clearly indicates that the sugars in these tetraplexes adopt preferentially an $\mathrm{S}$ type (C2'endo) geometry. In addition we can notice the emergence of an absorption at $920 \mathrm{~cm}^{-1}$ which may reflect the existence of guanosines in syn conformation. Such a band had been previously observed in the left-handed $Z$ form spectra and is probably related to a C-N vibration in syn guanosines [44]. 
The antisymmetric stretching vibration band of the phosphate groups is located at $1222 \mathrm{~cm}^{-1}$, indicative of a "B-like" geometry (figure $3 e, \mathrm{f}$ ). We observe on the spectra of the antiparallel tetraplexes recorded in $\mathrm{H}_{2} \mathrm{O}$ solutions the presence of an absorption at $1180 \mathrm{~cm}^{-1}$. Two contributions are found for the symmetric stretching vibration located at 1091 and $1082 \mathrm{~cm}^{-1}$. We propose that the presence of this doublet can be considered as indicative of the formation of a tetraplex, whatever the strand orientation, as it has been systematically observed in all structures studied here.

3.3. Interconversion of telomere DNA between antiparallel and parallel tetraplex structures.

The FTIR spectra of $d\left(G_{4} T_{3} G_{4}\right)-K^{+}, \quad d\left(G_{4} T_{4} G_{4}\right)-C^{2+}, d\left(\left(G_{4} T_{4}\right)_{3} G_{4}\right)-C^{2+}$ and $\mathrm{d}\left(\mathrm{G}_{3} \mathrm{~T}_{2} \mathrm{AG}_{3}\right)-\mathrm{K}^{+}$are presented in figure 5 (right panel). The different features characteristics of the G-tetraplex formation are also observed on these spectra. The band located at $1537 \mathrm{~cm}^{-1}$ characteristic of vibrations of guanines containing N7 atoms involved in hydrogen bonding is not affected by the exchange of $\mathrm{Na}^{+}$by $\mathrm{K}^{+}$ ions or by the addition of $\mathrm{Ca}^{2+}$ ions. However we observe on these spectra that the absorption assigned to the $\mathrm{C} 6=\mathrm{O} 6$ guanine carbonyl stretching vibration is now located at $1692 \mathrm{~cm}^{-1}$. This position, as discussed above, is characteristic of a parallel stranded tetraplex. This shows that $\mathrm{K}^{+}$or $\mathrm{Ca}^{2+}$ ions induce a structural transition of these telomeric sequences from antiparallel to parallel tetraplex structures.

In sequences containing only thymidines such as $\mathrm{dT}_{12}$ the $\mathrm{C} 2=\mathrm{O} 2$ stretching vibration is observed at $1695 \mathrm{~cm}^{-1}$ (figure 2a). In the case of the parallel structures of Oxytricha nova and human telomeric repeats, the thymine $\mathrm{C} 2=\mathrm{O} 2$ stretching vibration band expected around this position is overlapped by the strong guanine 
carbonyl band located at $1692 \mathrm{~cm}^{-1}$. On the contrary in the spectra of these parallel structures we observe very clearly the thymine $\mathrm{C} 4=\mathrm{O} 4$ stretching vibration located at $1663 \mathrm{~cm}^{-1}$ due to the shift to higher wavenumbers of the guanine contribution (figure 5 , right panel).

The sugar pucker remains unaffected by the addition of $\mathrm{K}^{+}$or $\mathrm{Ca}^{2+}$ ions, as shown by the presence of an absorption around $836 \mathrm{~cm}^{-1}$ (C2'-endo conformation) and the absence of any contribution around 865 and $805 \mathrm{~cm}^{-1}$ (C3'-endo conformation).

\section{Discussion}

In the present work we have proposed a new FTIR marker band allowing to characterize the strand orientation in $\mathrm{G}$ tetraplexes: in parallel structures the $\mathrm{C} 6=\mathrm{O} 6$ carbonyl stretching vibration is found at $1693 \mathrm{~cm}^{-1}$ while in antiparallel structures it is observed at $1682 \mathrm{~cm}^{-1}$. Moreover we have obtained the vibrational spectroscopic signatures of the $d\left(G_{4} T_{4} G_{4}\right)$ and $d\left(\left(G_{4} T_{4}\right)_{3} G_{4}\right)$ Oxytricha nova and $d\left(G_{3} T_{2} A G_{3}\right)$ human telomere sequences in both antiparallel and parallel $G$ tetraplex structures. The structural transition from an antiparallel to parallel $G$ tetraplex structure was detected by the shift of the $\mathrm{C} 6=\mathrm{O} 6$ carbonyl band.

Differences in the species of coordinated cations, even the ratio $\mathrm{Na}^{+}$versus $\mathrm{K}^{+}$, have been proposed to explain the formation of different tetraplex conformations for the same oligonucleotide sequence. The ability of these two cations to stabilize folded versus linear tetraplexes differs considerably when the oligonucleotides studied contain two or more guanine stretches [14]. Moreover the kinetics of the formation of antiparallel and parallel G tetraplex structures are very different. Linear four stranded tetraplexes have slow formation kinetics [45] while unimolecular tetraplexes fold rapidly [46]. Potassium and calcium ions are able not only to regulate the stability of 
G-tetraplexes, but also can induce a structural transition from an antiparallel to parallel G-tetraplex structure [29, 30, 47-49]. FTIR spectroscopy allows us to follow such a transition and precise the strand orientations in the formed tetraplexes using the guanine carbonyl stretching vibration as probe. For instance, we have observed by FTIR spectroscopy that $d\left(G_{3} T_{4} G_{3}\right)$ and $d\left(G_{4} T_{4} G_{4}\right)$ sequences can exhibit a mixture of antiparallel and parallel G tetraplex structures (data not shown). After a slow exchange only the parallel structure was detected. Thus, we propose that $\mathrm{K}^{+}$ and $\mathrm{Ca}^{2+}$ ions destabilize the antiparallel G-tetraplex structures and induce a slow transition to a parallel structure which affects the stacking interactions between the $G$ tetrads. This change in the stacking between the guanine tetrads is detected by the position of the carbonyl stretching vibration.

In conclusion we have characterized, using FTIR spectroscopy, the formation of guanine tetrads, basic motif stabilizing the tetraplexes formed by $\mathrm{G}$ rich DNA or RNA sequences. Involvement of N7 atoms and $\mathrm{C} 6=\mathrm{O} 6$ carbonyl groups in hydrogen bonding consistent with the $G$ tetrad model shown in scheme 1 has been shown. The sugar pucker in parallel as in antiparallel tetraplexes has been found to belong to the $S$ type family ( $\mathrm{C}^{\prime}$-endo geometry). On the contrary, the phosphodiester chains of the strands do not adopt an uniform conformation and differ from the classical conformations encountered in duplexes. The splitting of the symmetric stretching vibration of the phosphate groups is indicative of the formation of a tetrameric structure. Finally we present a new IR marker allowing to distinguish between four stranded intermolecular parallel tetraplexes and two stranded or singlestranded antiparallel tetraplexes. The interconversion between parallel and antiparallel structures for the same G-rich sequences induced by different ions can 
thus be followed. This conformational transition may play an important role in the interactions between potential drugs and genomic telomeric DNA G rich sequences.

\section{Acknowledgement}

M. Romero Guzmán was supported by a grant from the Ministry of the National Council of Science and Technology of Mexico (Conacyt).

\section{References}

1. S. Neidle, G.N. Parkinson, Curr. Opin. Struct. Biol. 13 (2003) 275-283.

2. D. Rhodes, L. Fairall, T. Simonsson, R. Court, L. Chapman, Embo Reports 12 (2002) 1139-1145.

3. H. Han, L.H. Hurley, Trends Pharmacol. Sci. 21 (2000) 136-142.

4. C.C. Chang, I.C. Kuo, I.F. Ling, C.T. Chen, H.C. Chen, P.J. Lou, J.J. Lin, T.C. Chang, Anal. Chem. 76 (2004) 4490-4494.

5. A.M. Burger, F. Dai, C.M. Schultes, A.P. Reszka, M.J. Moore, J.A. Double, S. Neidle, Cancer Res. 65 (2005) 1489-1496.

6. M. Ushigome, T. Ubagai, H. Fukuda, N. Tsuchiya, T. Sugimura, J. Takatsuka, H. Nakagama, Int. J. Oncol. 26 (2005) 635-640.

7. G.V. Tolstonog, G. Li, R.L. Shoeman, P. Traub, DNA Cell Biol. 24 (2005) 85110.

8. G.H. Yanez, S.J. Khan, A.M. Locovei, I.M. Pedroso, T.M. Fletcher, Biochem. Biophys. Res. Commun. 328 (2005) 49-56.

9. T. Lemarteleur, D. Gomez, R. Paterski, E. Mandine, P. Mailliet, J.F. Riou, Biochem. Biophys. Res. Commun. 323 (2004) 802-808.

10. A. Ambrus, D. Chen, J. Dai, R.A. Jones, D. Yang, Biochemistry 44 (2005) 2048-2058.

11. J. Seenisamy, S. Bashyam, V. Gokhale, H. Vankayalapati, D. Sun, A. Siddiqui-Jain, N. Streiner, K. Shin-Ya, E. White, W.D. Wilson, L.H. Hurley, J. Am. Chem. Soc. 127 (2005) 2944-2959.

12. D.E. Gilbert, J. Feigon, Curr. Opin. Struct. Biol. 9 (1999) 305-314. 
13. T. Simonsson, Biol. Chem. 382 (2001) 621-628.

14. R.H. Shafer, I. Smirnov, Biopolymers 56 (2001) 209-227.

15. M.A. Keniry, Biopolymers 56 (2001) 123-146.

16. Y. Wang, D.J. Patel, J. Mol. Biol. 234 (1993) 1171-1183.

17. G. Laughlan, A.I.H. Murchie, D.G. Norman, M.H. Moore, P.C. Moody, D.M.J. Lilley, B. Luisi, Science 265 (1994) 520-524.

18. K. Phillips, Z. Dauter, A.I.H. Murchie, D.M.J. Lilley, B. Luisi, J. Mol. Biol. 273 (1997) 171-182.

19. C.H. Kang, X. Zhang, R. Ratliff, R. Moyzis, A. Rich, Nature 356 (1992) 126131.

20. F.W. Smith, J. Feigon, Nature 356 (1992) 164-168.

21. S. Haider, G.N. Parkinson, S. Neidle, J. Mol. Biol. 320 (2002) 189-200.

22. Y. Wang, D.J. Patel, J. Mol. Biol. 251 (1995) 76-94.

23. F.W. Smith, P. Schultze, J. Feigon, Structure 3 (1995) 997-1008.

24 Y. He, R.D. Neumann, I.G. Panyutin, Nucleic Acids Res. 32 (2004) 53595367.

25. C.C. Hardin, A.G. Perry, K. White, Biopolymers 56 (2001) 147-194.

26. P. Balagurumoorthy, S.K. Brahmachari, D. Mohanty, M. Bansal, V. Sasisekharan, Nucleic Acids Res. 20 (1992) 4061-4067.

27. A.T. Phan, D.J. Patel, J. Am. Chem. Soc. 125 (2003) 15021-15027.

28. Y. Wang, D.J. Patel, Structure 1 (1993) 263-282.

29. G.N. Parkinson, M.P.H. Lee, S. Neidle, Nature 417 (2002) 876-880.

30. D. Miyoshi, A. Nakao, N. Sugimoto, Nucleic Acids Res. 31 (2003) 1156-1163.

31. E. Taillandier, J. Liquier, in J.M. Chalmers and P.R. Griffith (Eds.), Vibrational Spectroscopy of Nucleic Acids, Handbook of Vibrational Spectroscopy, John Wiley \& sons, Chichester, (2002), vol. 5, Chapter 2.

32. J.A. Mondragón-Sánchez, J. Liquier, M. Cheron, S.M. Gryaznov ,

E. Taillandier, J. Mol. Struct. 748 (2005) 27-37.

33. H.T. Miles, J. Frazier, Biochem. Biophys. Res. Commun. 49 (1972) 199-204.

34. M. Tsuboï, Applied Spectroscopy Rev. 3 (1969) 45-90.

35. R. Navarro, F. Peral, E. Gallego, J. Morcillo, J. Mol. Struct. 143 (1986) 357360.

36 J.A. Walmsley, M.L. Schneider, P.J. Farmer, J.R. Cave, C.R. Toth, R.M. Wilson, J. Biomol. Struct. Dyn. 10 (1992) 619-638.

37. F.B. Howard, J. Frazier, H.T. Miles, Biopolymers 16 (1977) 791-809. 
38. P. Carmona, M. Molina, J. Phys. Chem. B 104 (2000) 7496-7501.

39. J. Liquier, E. Taillandier, in H.H. Mantsch and D. Chapman (Eds), Infrared Spectroscopy of Biomolecules, Wiley-Lyss (1996) p. 131-158.

40 P. Balagurumoorthy, S.K. Brahmachari, J. Biol. Chem. 269 (1994) 21858-21869.

41 P. Balagurumoorthy, S.K. Brahmachari, Ind. J. Biochem. Biophys. 32 (1995) 385-390.

42. A.A. Maevsky, B.I. Sukhorukov, Nucleic Acids Res. 8 (1980) 3029-3042.

43. J.A. Taboury, J. Liquier, E. Taillandier, Can. J. Chem. 63 (1985) 1904-1909.

44 L. Petraccone, E. Erra, V. Esposito, A. Randazzo, L. Mayol, L. Nasti, G. Barone, C. Giancola, Biochemistry 43 (2004) 4877-4884.

45. J.R. Wyatt, P.W. Davis, S.M. Freier, Biochemistry 35 (1996) 8002-8008.

46. I. Smirnov, R.H. Shafer, Biochemistry 39 (2000) 1462-1468.

47. D. Miyoshi, A. Nakao, T. Toda, N. Sugimoto, FEBS Lett. 496 (2001) 128-133.

48. C.C. Hardin, E. Henderson, T. Watson, J.K. Prosser, Biochemistry 30 (1991) 4460-4472.

49. G.D. Strahan, M.A. Keniry, R.H. Shafer, Biophys. J. 75 (1998) 968-981. 


\section{Figure captions}

Scheme 1: arrangement of hydrogen bonds between guanines in a $\mathrm{G}$ tetrad.

Figure1: FTIR spectra recorded in $\mathrm{D}_{2} \mathrm{O}$ solutions at $5^{\circ} \mathrm{C}$ in the region of the in-plane double bond base stretching vibrations of parallel stranded tetraplexes with $1 \mathrm{Na}^{+}$ion per phosphate:

a) $d G_{12} ;$ b) $\left.d\left(G_{4} T G_{4}\right) ; c\right) d\left(T_{9} G_{5}\right)$

Figure 2: FTIR spectra recorded in $\mathrm{D}_{2} \mathrm{O}$ solutions in the region of the in-plane double bond base stretching vibrations of:

a) $\mathrm{dT}_{12}$; b) $5^{\prime}-\mathrm{dGMP}\left(\mathrm{T}=5^{\circ} \mathrm{C}\right)$; c) $5^{\prime}-\mathrm{dGMP}\left(\mathrm{T}=95^{\circ} \mathrm{C}\right)$

Figure 3: FTIR spectra recorded in $\mathrm{H}_{2} \mathrm{O}$ solutions in the region of the phosphate group stretching vibrations of:

a) $\mathrm{d}\left(\mathrm{C}_{3} \mathrm{GCG}_{3}\right)_{2}$ Watson-Crick double helical $A$ conformation (film at $58 \%$ relative humidity). b) $d\left(\mathrm{C}_{3} \mathrm{GCG}_{3}\right)_{2}$ Watson-Crick double helical B conformation (film at $90 \%$ relative humidity). c) $d G_{12}\left(\mathrm{Na}^{+}\right)$parallel tetraplex d) $d\left(G_{4} T_{G}\right)\left(\mathrm{Na}^{+}\right)$parallel tetraplex; e) $d\left(G_{4} T_{4} G_{4}\right)\left(N^{+}\right)$antiparallel tetraplex; f) $d\left(G_{3} T_{2} A_{G}\right)\left(N^{+}\right)$antiparallel tetraplex.

Right panel: same spectra in the $1150-1030 \mathrm{~cm}^{-1}$ region with expanded ordinate scale.

Figure 4: FTIR spectra recorded in $\mathrm{D}_{2} \mathrm{O}$ solutions in the region of sugar-phosphate backbone vibrations of:

left panel: parallel tetraplexes a) $d G_{12} ;$ b) $d\left(G_{4} T G_{4}\right)$; c) $r G_{7}$. right panel: antiparallel tetraplexes d) $\left.\left.d\left(G_{4} T_{3} G_{4}\right) ; e\right) d\left(G_{4} T_{4} G_{4}\right) ; f\right) d\left(G_{3} T_{2} A G_{3}\right)$

Figure 5: FTIR spectra recorded in $\mathrm{D}_{2} \mathrm{O}$ solutions at $5^{\circ} \mathrm{C}$ in the region of the in-plane double bond base stretching vibrations of:

Left panel : antiparallel stranded tetraplexes $\left(1 \mathrm{Na}^{+}\right.$per phosphate)

a) $d\left(G_{4} T_{3} G_{4}\right) ;$ b) $d\left(G_{4} T_{4} G_{4}\right)$; c) $\left.d\left(\left(G_{4} T_{4}\right)_{3} G_{4}\right) ; d\right) d\left(G_{3} T_{2} A G_{3}\right)$

Right panel: parallel stranded tetraplexes formed by the same sequences in presence of $\mathrm{K}^{+}(\mathrm{a}$ and $\mathrm{d})$ or $\mathrm{Ca}^{2+}(\mathrm{b}$ and $\mathrm{c})(2$ ions per molecule). 
Table 1 : position of the guanine $\mathrm{C} 6=\mathrm{O} 6$ carbonyl stretching vibration in the FTIR spectra of parallel and antiparallel tetraplexes (in $\mathrm{cm}^{-1}$ )

\begin{tabular}{|c|c|c|c|c|c|c|c|}
\hline \multicolumn{3}{|c|}{ Parallel tetraplexes } & \multicolumn{3}{|c|}{ Antiparallel tetraplexes } & \multicolumn{2}{|c|}{ Free guanosines } \\
\hline \multirow{2}{*}{$\begin{array}{l}\mathrm{dG}_{\mathrm{n}} \\
\mathrm{rG}\end{array}$} & \multirow{2}{*}{$\begin{array}{l}1696 \\
1696\end{array}$} & \multirow{2}{*}{$\frac{\mathrm{Na}^{+}}{\mathrm{Na}^{+}}$} & & & & \multirow{2}{*}{$\begin{array}{l}\text { 5'-dGMP } \\
\text { 5'-GMP }\end{array}$} & \multirow{2}{*}{$\begin{array}{l}1666 \\
1665 \\
{[33]}\end{array}$} \\
\hline & & & & & & & \\
\hline$r G_{n}$ & 1695 & $\mathrm{Na}^{+}$ & & & & & \\
\hline$d G_{12-18}$ & 1695 & $\mathrm{Na}^{+}$ & & & & & \\
\hline $\mathrm{d}\left(\mathrm{G}_{4} \mathrm{TG}_{4}\right)$ & 1694 & $\mathrm{Na}^{+}$ & & & & & \\
\hline $\mathrm{d}\left(\left(\mathrm{G}_{4} \mathrm{~T}_{4}\right)_{3} \mathrm{G}_{4}\right.$ & 1694 & $\mathrm{Ca}^{2+}$ & $\mathrm{d}\left(\left(\mathrm{G}_{4} \mathrm{~T}_{4}\right)_{3} \mathrm{G}_{4}\right)$ & 1679 & $\mathrm{Na}^{+}$ & & \\
\hline $\mathrm{d}\left(\mathrm{TGT}_{5} \mathrm{G}_{6}\right)$ & 1693 & $\mathrm{Na}^{+}$ & & & & & \\
\hline $\mathrm{dG}_{12}$ & 1692 & $\mathrm{Na}^{+}$ & & & & & \\
\hline $\mathrm{d}\left(\mathrm{T}_{9} \mathrm{G}_{5}\right)$ & 1692 & $\mathrm{Na}^{+}$ & & & & & \\
\hline $\mathrm{d}\left(\mathrm{G}_{4} \mathrm{~T}_{3} \mathrm{G}_{4}\right)$ & 1691 & $\mathrm{~K}^{+}$ & $\mathrm{d}\left(\mathrm{G}_{4} \mathrm{~T}_{3} \mathrm{G}_{4}\right)$ & 1683 & $\mathrm{Na}^{+}$ & & \\
\hline $\mathrm{d}\left(\mathrm{G}_{3} \mathrm{~T}_{2} \mathrm{AG}_{3}\right)$ & 1691 & $\mathrm{~K}^{+}$ & $\mathrm{d}\left(\mathrm{G}_{3} \mathrm{~T}_{2} \mathrm{AG}_{3}\right)$ & 1680 & $\mathrm{Na}^{+}$ & & \\
\hline $\mathrm{d}\left(\mathrm{G}_{4} \mathrm{~T}_{4} \mathrm{G}_{4}\right)$ & 1690 & $\mathrm{Ca}^{2+}$ & $\mathrm{d}\left(\mathrm{G}_{4} \mathrm{~T}_{4} \mathrm{G}_{4}\right)$ & 1685 & $\mathrm{Na}^{+}$ & & \\
\hline & & & $\mathrm{d}\left(\mathrm{G}_{3} \mathrm{~T}_{4} \mathrm{G}_{3}\right)$ & 1681 & $\mathrm{~K}^{+}$ & & \\
\hline & & & $\mathrm{d}\left(\mathrm{T}_{2} \mathrm{AG}_{3}\right)_{4}$ & 1680 & $\mathrm{~K}^{+}$ & & \\
\hline & rage & & & & & & $\begin{array}{l}\text { age } \\
66\end{array}$ \\
\hline
\end{tabular}




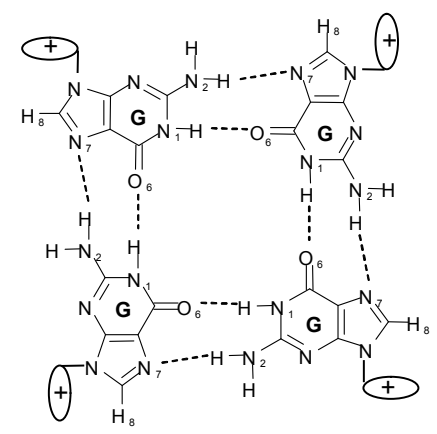

Sheme1

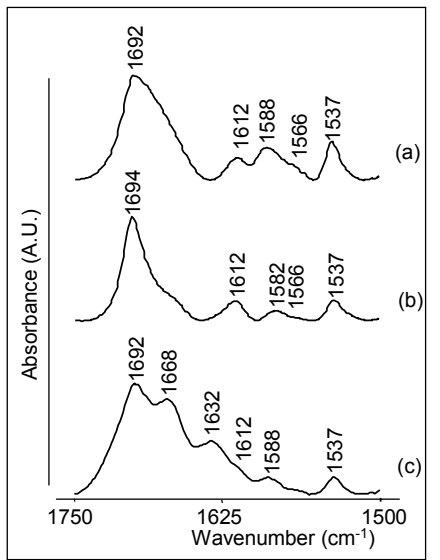

Figure 1 


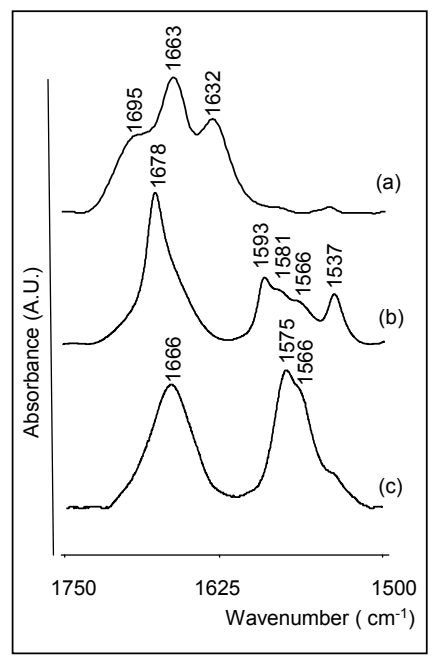

Figure 2

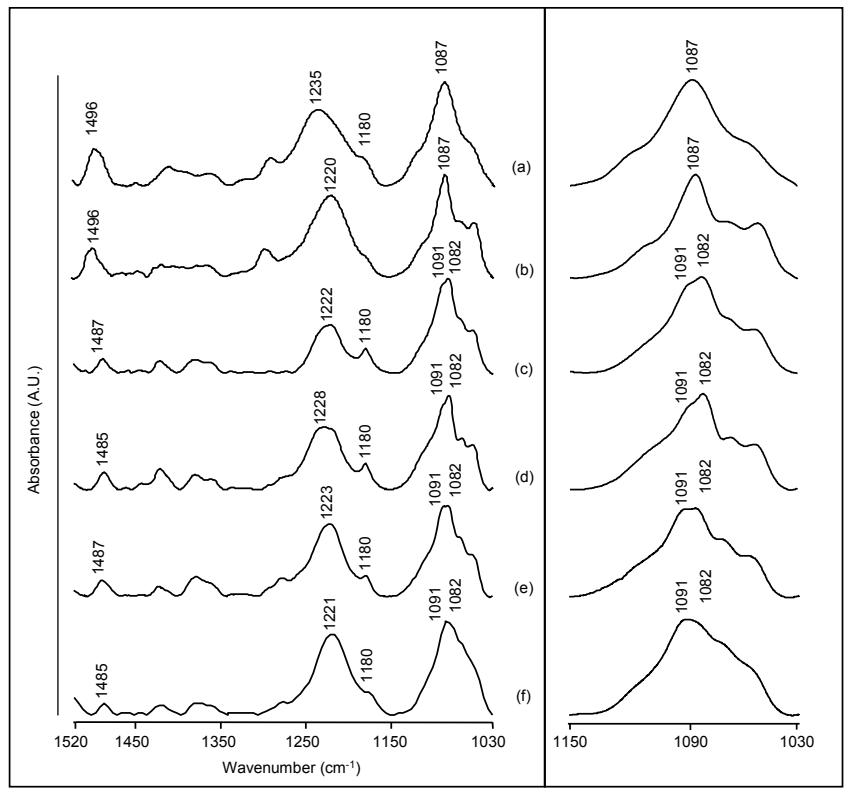

Figure 3 

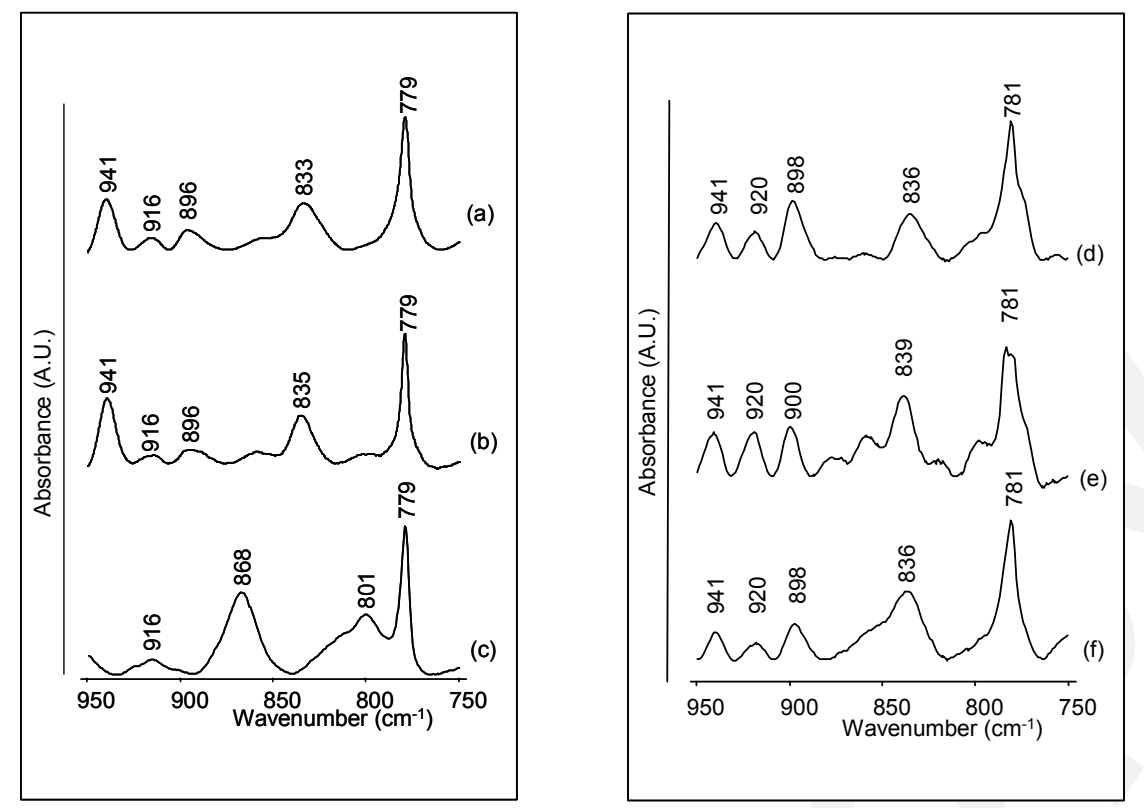

Figure 4
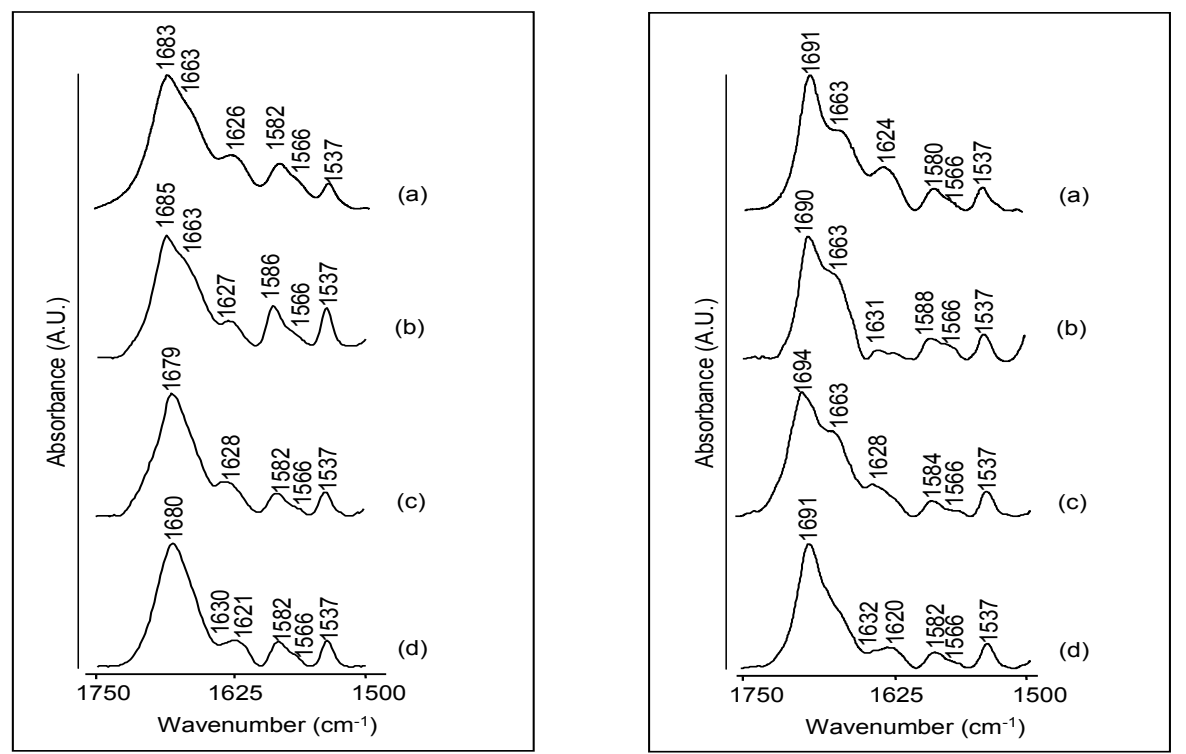

Figure 5 